\title{
STRATEGI BELAJAR KELOLOSAN JAPANESE LANGUAGE PROFICIENCY TEST N1 (STUDI KASUS MAHASISWA SASTRA JEPANG)
}

\author{
Agus Budi Cahyono, Nadya Inda Syartanti \\ Universitas Brawijaya, agusbcahyono@yahoo.com \\ Universitas Brawijaya, nadya.inda.sy@gmail.com
}

\begin{abstract}
Japanese Language Proficiency Test (JLPT) organized by The Japan Foundation twice a year in July and December is an international test which aims to measure the Japanese language skill of Japanese language learners around the world. JLPT has 5 levels in which level N5 is the lowest or basic level, while N1 is the highest or proficient level which is considered on par with the Japanese native speakers. Level IV students in school year 2016/2017 who have been able to achieve JLPT level N1 are proud achievements for Japanese Literature Study Program of Brawijaya University. Therefore, this research aims to see the learning strategy of Japanese language used by students who achieved JLPT level N1 in period II of 2016. In fact, they never visit Japan to stay, study, or even travel. The learning strategies of students studied through foreign language learning strategy as revealed by Oxford (1990) are memory, cognitive, and compensation in the category of direct strategy as well as metacognitive, affective, and social strategies in the category of indirect strategy. The used research methodology is qualitative research methodology of case study through questionnaire, interview, and observation. The research shows the result that learning strategy of Japanese language used by students to achieve JLPT level N1 are memory, cognitive, metacognitive, and compensation strategies by using several medias from anime (Japanese cartoon), Japanese movie, video game, Japanese songs, and even Japanese books like manga (Japanese comic) and novel. These students seldom use affective and social strategies. It is known from their lecturer that these students are less proficient in socialization and oral production.
\end{abstract}

Keywords: JLPT, learning strategy, foreign language learning strategy, Japanese language learning strategy.

\section{PENDAHULUAN}

Dalam dunia global sekarang ini sangat penting memiliki kompetensi tertentu. Dengan kompetensi itu seseorang diharapkan untuk dapat mengantisipasi, merespon, dan memanagetrend global. Jika seseorang tidak memiliki kompetensi yang dibutuhkan dalam hidup ini, maka orang tersebut terpinggir. Namun sebaliknya, jika seseorang memiliki kompetensi, maka orang 
tersebut dapat survive. Agar mahasiswa Program Studi Sastra Jepang Universitas Brawijaya tidak menjadi pihak yang terpinggir dalam hidup setelah menyelesaikan masa studinya, maka Program Studi Sastra Jepang Universitas Brawijaya mensyaratkan mahasiswa untuk lulus dengan kompetensi keterampilan berbahasa minimal Japanese Language Proficiency Test (JLPT) N3.

Berdasar hasil penelitian yang telah dilakukan oleh Cahyono (2015: 15), banyak lulusanProgram Studi Sastra Jepang Universitas Brawijaya tidak dapat terserap ke dunia kerja yang terkait dengan dunia kejepangan (tidak menggunakan bahasa Jepang) sebab tidak memiliki sertifikat minimal JLPT N3. Bahkan ada yang lebih ekstrim lagi, yaitu ada stake holder yang mensyaratkan pelamar fresh graduate pembelajar bahasa Jepang di Perguruan Tinggi untuk memiliki JLPT N2 dikarenakan inilah kualifikasi utama yang harus dimiliki lulusan agar survive setelah lulus kuliah. Ini berarti meskipun lulusan tersebut memiliki Indeks Prestasi Kumulatif dengan rata-rata minimal 3 ke atas, namun jika tidak memiliki sertifikat JLPT N3, maka kemungkinan besar lamaran pekerjaan lulusan tersebut tidak lolos seleksi administrasi tinggi.

Japanese Language Proficiency Test (JLPT)merupakanujian sebagai pengakuan yang menyatakan kompetensibahasa Jepang seseorang yang bahasa ibunya bukanbahasa Jepang.JLPT dimulai pada tahun 1984 oleh Japan Foundation (Kokusai Kouryuu Kikin) di Jepang. Jumlah peserta dari berbagai negara yang mengikuti JLPT Jepang pertama kali adalah 7000 orang. Pada tahun 2009 meningkat menjadi 770.000 peserta, semenjak itu JLPT menjadi ujian bahasa Jepang terbesar di dunia (http://www.jlpt.jp/e/statistics).JLPT terbagi menjadi 5 tingkat, yaitu N1, N2, N3, N4 dan N5. Tingkat terbawah dan termudah adalah N5, sedangkan tingkat tertinggi dan tersulit adalah N1. Materi yang diujikan dalam JLPT adalah kanji, goi(kosa kata), bunpo (tata bahasa), dokkai (membaca) dan chokai (menyimak). Waktu pengerjaan N5 selama 105 menit, N4 
Agus Budi Cahyono, Nadya Inda Syartanti, Strategi Kelolosan Belajar...(hlm. 43- 54)

selama 125 menit, N3 selama 140 menit, N2 selama 155 menit dan N1 selama 170 menit.

Ujian JLPT ini diadakan 2 kali setahun di Jepang, yaitu pada bulan Juli dan Desember.Di negara lain kebanyakan sekali dalam 1 tahun. Di Indonesia dilaksanakan di 8 kota, yaitu Jakarta, Bandung, Yogyakarta, Surabaya, Denpasar, Medan, Padang dan Malang. Pelaksanaan 2 kali setahun dimulai di Jakarta pada tahun 2013, dan di Surabaya pada tahun 2015.Mulai Desember 2016 Malang menjadi kota ke-8 sebagai kota penyelenggara JLPT, danUniversitas Brawijaya diberi kepercayaan sebagai tempat ujian. Pada periode ujian ke-2, yaitu bulan Desember tahun 2016, peserta yang mendaftar di Universitas Brawijaya sebanyak 976 peserta. N5 sebanyak 345 orang, N4 sebanyak 213 orang, N3 sebanyak 287 orang, N2 sebanyak 91 orang, N1 sebanyak 40 orang. Dari 40 peserta N1 ada 2 mahasiswa tingkat IVyang lolos N1, padahal Program Studi Sastra Jepang Universitas Brawijaya hanya menginginkan mahasiswanya minimal lolos N3 saja selama mengikuti proses belajar mengajar.

Kelolosan 2 mahasiswa tersebut tidaklah dapat dilepaskan dari proses pembelajaran bahasa Jepang di Program Studi Sastra Jepang Universitas Brawijaya, yang mana proses pembelajaran ini merupakan satu kesatuan dan melibatkan beberapa komponen. Komponen-komponen tersebut meliputi pengajar (dosen), pembelajar (mahasiswa), rencana pengajaran, media ajar, strategi pengajaran, dan penilaian. Padahal menurut penuturan salah satu mahasiswa tersebut bahwapemerolehan bahasa Jepang setara level $\mathrm{N} 1$ dalam proses pembelajaran di kelas sangat sedikit sekali, ditambah mahasiswa tersebutbelum pernah sama sekali ke Jepang ketika menempuh studi di Program Studi Sastra Jepang Universitas Brawijaya. Namun karena semangat dan motivasi yang tinggi, akhirnya mahasiswa tersebut dapat lolos JLPT N1.Lolosnya 2 mahasiswa memperoleh JLPT N1 menambah fakta bahwajumlah mahasiswa Program Studi 
Sastra Jepang Universitas Brawijayayang lulus dengan yang tidak lulus JLPT N3, $\mathrm{N} 2$ atau N1sangatlah besar sekali, sehingga hal ini menarik perhatian penulis untuk melakukan penelitian lebih lanjut tentang strategi belajar mahasiswa dalam mempelajari sesi soalgengo chisiki (pengetahuan bahasa terdiri dari kanji,kosakata dan tata bahasa), dokkai (pemahaman bacaan), dan chokai (menyimak) yang merupakan bagian dari soal ujian JLPT.

Tiap pembelajar bahasa asing, khususnya bahasa Jepang tentulah mempunyai strategi atau gaya belajar sendiri-sendiri. Ada yang sering memakai media cetak, media komputer, media online, ataupun lebih suka langsung berkomunikasi dengan para pembelajar bahasa yang sama, ataupun dengan native speaker.Oxford (1990, 1990:16-17) membagi strategi belajar asing menjadi 2 bagian besar, yaitu langsung dan tidak langsung. Strategi langsung dibagi lagi menjadi 3: (a)memori, (b)kognitif, dan (c)kompensasi, sedangkan strategi tak langsung dibagi menjadi 3: (d)metakognitif, (e)afektif, dan (f)sosial.

a. Memori

Strategi belajar memori digunakan oleh pembelajar dengan memanfaatkan pengetahuan dan pengalaman belajar sebelumnya. Strategi belajar ini banyak melibatkan ingatan dan proses pembelajaran yang menggunakan daya ingat.

b. Kognitif

Strategi kognitif adalah segala perilaku pembelajar dalam proses belajar mengajar yang berhubungan dengan penggunaan daya pikir pembelajar.

c. Kompensasi

Strategi belajar kompensasi digunakan pembelajar yang telah memiliki ketrampilan cukup tinggi. Strategi belajar ini biasanya dimanfaatkan untuk menanggulangi beberapa keterbatasan dalam berbahasa.

d. Metakognitif

46 | http://journal.unesa.ac.id/index.php/paramasastra 
Strategi metakognitif adalah segala perilaku pembelajar yang berhubungan dengan taktik atau cara pembelajar untuk menghadapi dan mengelola bahan belajar mengajar.

e. Afektif

Strategi afektif adalah segala perilaku pembelajar yang berhubungan dengan sikap dan perasaan pembelajar dalam menghadapi proses belajar. Strategi ini lebih lanjut dibagi menjadi: afektif positif dan afektif negatif. Afektif positif adalah perilaku pembelajar yang menunjukkan menerima dan menghargai proses belajar mengajar. Afektif negatif adalah kebalikan dari afektif positif.

Bagi seorang pengajar, salah satu cara untuk mendorong peserta didik untuk terlibat secara aktif adalah dengan menunjukkan pada mereka seperti apa sebenarnya para pembelajar bahasa asing itu belajar dengan baik dan benar strategi belajarnya. Jhonson (2001:149-150, dalam Santoso, paragraf 6) mengatakan bahwa pembelajar bahasa yang baik memiliki 5 (lima) ciri,yaitu :

1. Pembelajar yang baik adalah pembelajar yang aktif berpartisipasi. Mereka secara sadar berusaha menciptakan suasana situasidimana mereka dapat menggunakan bahasa yang dipelajarinya.

2. Pembelajar bahasa yang baik menyadari bahwa bahasa adalah sistem. Mereka menunjukkan kemauan yang kuat untuk mempelajari tata bahasa bahasa asing yang dipelajarinya.

3. Pembelajar yang baik juga memandang bahasa sebagai alatkomunikasi. Karena itu,mereka juga berusaha untuk dapatmelakukan komunikasi dengan orang lain dalam bahasa yang dipelajarinya pada situasi riil, termasuk juga dengan penutur asli. Dengan cara seperti ini, mereka akan memiliki pengalaman nyata bahwa bahasa yang dipelajarinya bisa digunakan dalam konteks sehari-hari. Cara seperti ini tidak secara langsung akan memperkuat proses internalisasi pengetahuan kebahasaan dalam diri mereka. Pembelajar 
seperti ini akan berusaha berbicara dengan native speaker bila ada kesempatan.

4. Pembelajar bahasa yang baik secara konsisten memonitor perkembangan kemampuan berbahasanya dan mau mengoreksi serta memperbaiki kesalahan yang dibuatnya. Di dalam sebuah kelas, misalnya ketika guru bertanya pada rekan sekelas, dia juga berusaha menjawab sendiri dalam hati dan membandingkan dengan jawaban yang diberikan rekannya.

5. Pembelajar yang baik menyadari bahwa mempelajari bahasa selaludomain afektif. Dengan demikian faktor minat, motivasi bahkan menemukan gaya belajar yang tepat sesuai dengan karakternya merupakan aspek-aspek yang harus digeluti olehpembelajar.

Jenis penelitian yang digunakan adalah penelitian kualitatif studi kasus.Yin (dalam Cresswell, 2015:135) menyatakan bahwa riset studi kasus mencakup studi tentang suatu kasus dalam kehidupan nyata, dalam konteks atau setting kontemporer. Cresswell (2015:135) berpendapatbahwa studi kasus adalah sebuah metodologi: satu jenis desain dalam penelitian kualitatif yang dapat berupa obyek penelitian dan juga hasil dari penelitian tersebut. Penelitian studi kasus adalah pendekatan kualitatif yang penulisnya mengeksplorasi kehidupan nyata, sistem terbatas kontemporer (kasus) atau beragam sistem terbatas (berbagai kasus) melalui pengumpulan data yang detail dan mendalam yang melibatkan beragam sumber informasi majemuk dan melaporkan deskripsi kasus dan tema kasus.Satuan analisis dalam studi kasus dapat berupa kasus majemuk atau kasus tunggal.

Tipe studi kasus kualitatif itu dibedakan berdasar ukuran batasan dari kasus tersebut.Misalnya apakah kasus tersebut melibatkan satu individu, beberapa individu, suatu kelompok, suatu program besar, atau suatu aktifitas.Studi kasus juga dapat dibedakan dalam hal tujuan dari analisa kasusnya. Ada tiga variasi dalam hal tujuan: studi instrumentunggal, studi kasus majemuk, dan studi kasus 
intrinsik. Studi kasus instrumental tunggal, peneliti memfokuskan pada persoalan, kemudian memilih satu kasus terbatas untuk mengilustrasikan persoalan ini.Dalam studi kasus kolektif, peneliti memilih beragam studi kasus untuk mengilustrasikan isu atau persoalan.Tipe studi kasus intrinsik yang berfokus pada kasus itu sendiri karena kasus tersebut menghadirkan situasi yang tidak biasa atau unik.

Pada penelitian kali ini, penulis hanya menggunakan 1 individu sebagai subyek penelitian, yaitu mahasiswa tingkat IV yang lolos JLPT N1 periode II tahun 2016 dan subyek penelitian ini tidak pernah pergi wisata atau pernah tinggal di Jepang. Varian tujuan yang dipakai adalah studi kasus intrinsik untuk pendalaman hasil penelitian.

Satu dari mahasiswa tingkat IV yang lolos tersebut berasal dari propinsi Jawa Timur, tepatnya kota Malang. Pada saat perkuliahan di Program Studi Sastra Jepang Universitas Brawijaya hanya memperoleh sedikit pembelajaran bahasa Jepang selevel N1. Pembelajaran bahasa Jepang selevel N1 ini diperoleh hanya ketika ada pembelajaran persiapan belajar ke Jepang untuk memperoleh beasiswa Ministry Of Education, Culture, Sports, Science and Technology (MEXT). Mahasiswa tersebut masuk ke Program Studi Sastra Jepang Universitas Brawijaya pada tahun 2012 karena ada ketertarikan terhadap bahasa dan budaya Jepang. Untuk mengukur kompetensi bahasa Jepangnya, mahasiswa tersebut mengikuti JLPT N1pada Desember 2016 saat masih duduk di semester 7 dan lolos dengan nilai total 105. Rincian nilaiterdiri atas gengo chisiki (huruf, kosakata, tata bahasa) dengan nilai 32, dokkai (membaca) dengan nilai 28, dan chokai (menyimak) dengan nilai 41.

Menurut Yin (2014:27-28), desain adalah kaitan logis antara data empiris dengan pertanyaan awal penelitian dan terutama konklusi-konlusinya.Cara berpikir lain tentang desain penelitian adalah sebagai blue printsuatu penelitian, 
berkenaan dengan sekurang-kurangnya empat masalah, yaitu pertanyaan apa yag harus diajukan, bagaimana data relevan, data yang harus dikumpulkan, dan bagaimana menganalisa hasilnya.

Desain penelitian yang digunakan dalam penelitian kali ini adalah kualitatif deskriptif denganmemanfaatkan cara penafsiran dalam bentuk deskripsi. Data dalam penelitian ini adalah hasil interviewdan pengamatan pada mahasiwa tingkat IVProgram Studi Sastra Jepang Universitas Brawijaya yang telah lolos JLPT N1periode II Desember 2016. Data juga dikumpulkan melalui interviewpada dosen yang mengampu mata kuliah yang diikuti oleh mahasiswa tersebut. Kasus dalam penelitian kali ini adalah satu mahasiswa tingkat IV yang lolos JLPT N1 periode II Desember 2016. Diharapkan dengan desain penelitian seperti ini dapat menghasilkan kesimpulan yang benar-benar valid intensitasnya sehingga memberikan informasi yang berguna untuk membantu mahasiswamahasiwa lain untuk kelolosan JLPT N2 ataupun N1.

Pengumpulan data dilakukan dengan cara memberikan kuesioner,observasi dan interviewhanya kepada satu mahasiswa tingkat IVProgram Studi Sastra Jepang Universitas Brawijayapada tahun ajaran 2016/2017. Kuesioner diberikan setelah mahasiswa tersebut lolos N1 pada ujian periode 2 bulan Desember 2016. Observasi dilakukan dengan mengamati ketika mahasiswa tersebut mengikuti proses pembelajaran di kelas ataupun di luar kelas. Interview dilakukan di ruang dosen untuk memperoleh data yang valid dan dalam. Di samping itu juga untuk memperoleh data sekunder, penulis melakukan interview kepada dosen pengampu mata kuliah supaya ada data pembanding apakah subyek penelitian benar-benar terlibat di dalam proses pembelajaran di kelas.

Ada tiga variasi tujuan penelitian studi kasus, yaitu studi kasus instrumental tunggal, studi kasus kolektif, dan studi kasus intrinsik. Dalam studi kasus instrumental tunggal (Stake , 1995 dalam Creswell halaman: 139), peneliti memfokuskan pada isu. Studi kasus kolektif, satu isu juga dipilih, tetapi penulis 
memilih beragam studi kasus untuk mengilustrasikan isu tersebut.Tipe terakhir adalah studi intrinsik yang memfokuskan pada kasusnya sendiri karena kasus tersebut menghadirkan situasi yang unik. Dalam penulisan ini yang dipakai adalah analisa kasus tipe terakhir, yaitu studi intrinsik dengan pertimbangan bahwa kasus mahasiswa yang lulus N1, namun belum pernah ke Jepang adalah termasuk kasus unik sehingga ada kelayakan untuk dijadikan data dengan memfokuskan pada strategi belajar perorangan mahasiswa tersebut.

\section{PEMBAHASAN}

Sebagaimana telah disebutkan sebelumnya, subyek penelitian adalah mahasiswa semester 7 Program Studi Sastra Jepang Universitas Brawijaya. Kuesioner diberikan pada tanggal 27 Januari 2017.Di kuesioner tersebut terdapat pertanyaan yang menyangkut strategi belajar subyek penelitian.Subyek penelitian sangat suka sekali melihat video game, animasi, dan lain-lain, yang semuanya tersaji dalam bahasa Jepang.Subyek penelitian mampumenghabiskan waktu tiap hari dengan durasi 3 sampai 4 jam untuk melihat animasi atau video game kesukaannya, yang kebanyakan bergenre sains fiksi. Di samping itu, subyek penelitian juga mendengarkan lagu-lagu Jepang yang menjadi lagu pembuka (theme song) dari animasi-animasi tersebut.Subyek penelitian banyak menghafalkan theme song film animasi tersebut,seperti salah satu contohtheme song yang dihafalkan adalah boken deshou deshou, puchi nashi no sekai, dan lainlain.Video game dan animasi diperoleh dengan mengunduh di internetyang dilakukan di rumah, kampus, dan lain-lain.Subyek penelitian akan mengulang sekali lagi bila tidak mengerti isi dari percakapan yang ada di video game dan animasi. Bahkan subyek penelitian banyak tidak memakai subtitle ketika memahami sebuah cerita yang ada di video game dan animasi. 
Subyek penelitian sering membaca novel bergenre sains fiksi.Dalam satu minggu subyek penelitian mampumenyelesaikan 2 sampai 3 jilid novel yang diupload oleh seseorang di internet, seperti novel berjudulJinrui wa suitai shimashita, Iriya no sora ufo no natsu, dan lain-lain. Dari kesukaan membaca bacaan berbahasa Jepangtersebut, subyek penelitian sudah mampu menebak alur cerita dari sebuah komik, novel ataupun cerita-cerita lainnya.Di samping itu juga, subyek penelitian sudah mampu menganalisa kalimat dari bentuk-bentuknya (tata bahasa). Subyek penelitian juga mampu memperkirakan kesulitan-kesulitan ketika akan membaca sebuah novel atau artikel ilmiah. Hal ini dibuktikan proposal penulisan skripsinya yang banyak mengambil dari artikel berbahasa Jepang.

Manga (komik Jepang), film animasi, drama Jepang, dan novel Jepang sangat digemari oleh subyek penelitian.Dari situ subyek penelitian belajar banyak tentang kosa kata, huruf kanji, ataupun tata bahasa yang tidak diajarkan di kelas. Ketika tidak mengerti kosa kata dalam sebuah narasi, maka subyek penelitianakan mencoba mencari clue antara narasi sebelumnya dengan narasi berikutnya. Jika masih tidak memahaminya, maka subyek penelitian secepatnya membuka kamus online yang ada komputer atau yang sudah terpasang di handphone. Huruf kanji yang sulitpun, dipelajari melalui pembelajaran online. Di internet tersaji cara pembelajaran kanji yang sulit, termasuk juga urutan penulisan dan jumlah coretannya juga ada. Kanji dengan cara yang berbedapun tersedia secara online. Semua itu tergantung pada kemauan dari pembelajar tersebut. Pembelajaran tata bahasa dilakukan dengan mengamati struktur gramatikal yang ada di dalam novel, artikel, film animasi, manga (komik Jepang), dan lain-lain.subyek penelitian banyak menemukan tata bahasa selevel dengan tata bahasa level N1yang tidak diajarkan di kelas. 
Agus Budi Cahyono, Nadya Inda Syartanti, Strategi Kelolosan Belajar...(hlm. 43- 54)

\section{SIMPULAN}

Penelitian ini dilakukan untuk menunjukkan bahwa mahasiswa yang tidak pernah tinggal di Jepang pun bisa lolos JLPT N1 jika mempunyai gaya dan strategi belajar sendiri. Subyek penelitian ini adalah salah satu mahasiswa tingkat IV Program Studi Studi Sastra Jepang Universitas Brawijaya yang telah lolos JLPT N1 periode II tahun 2016. Pemilihan mahasiswa tingkat IV ini dilalukan karena mahasiswa tersebut telah lolos JLPT N1 padahal tidak pernah tinggal di Jepang sama sekali.

Metode penelitian yang dipakai adalah metode penelitian kualitatif studi kasus. Teori pembelajaran bahasa asing untuk menjawab rumusan masalah adalah teori Oxford (1990). Dari hasil kuesioner, interview, dan observasi diperoleh strategi belajar bahasa asing yang dipakai oleh subyek penelitian adalah memori, kognitif, metakognitif, dan kompensasi. Subyek penelitian sedikit sekali memakai strategi afektif dan sosial. Beberapa dosen pengampu menuturkan bahwa subyek penelitian kurang cakap bersosialisasi dan oral production.

\section{DAFTAR RUJUKAN}

Al Wasilah, Chaedar. 2015. Pokoknya Studi Kasus Pendekatan Kualitatif. Bandung: Kiblat Buku Utama.

Cahyono, Agus Budi, Efrizal, Fitriana Puspita Dewi. 2015. Tingkat Relevansi

Lulusan Prodi Sastra Jepang.Malang: Universitas Brawijaya. Laporan Penelitian Tidak diterbitkan.

Creswell W., John. 2015. Penelitian Kualitatif dan Desain Riset.Yogyakarta: Pustaka Pelajar.

Oxford, R.L. 1990. Language LearningStrategies: What Every Teacher Should Know. New York: Newbury House

Pranowo. 2015. Teori Belajar Bahasa. Yogyakarta: Pustaka Pelajar. 
Ratna, Nyoman Kutha. 2010. Metodologi Penelitian Kajian Ilmu Budaya dan Sosial Humaniora. Yogyakarta: Pustaka Pelajar.

Yin, Robert K. 2014. Studi Kasus Desain dan Metode. Depok: Rajawali Press.

Fariqah. Diakses dari lib.unnes.ac.id/16893/1/1103504029.pdf pada Mei 2016.

Santoso, Iman. Diakses dari http://staff.uny.ac.id/sites/default/files/Menjadi\%20Pembelajar\%20Bahasa\% 20Asing\%20yang\%20Baik.pdf pada Mei 2016. 